Portland State University

PDXScholar

\title{
Corrosion Behavior of Copper Thin Films in Organic HF-Containing Cleaning Solution for Semiconductor Applications
}

\author{
Nabil George Mistkawi \\ Portland State University \\ Makarem A. Hussein \\ Malgorzata Ziomek-Moroz \\ U.S. Department of Energy \\ Shankar B. Rananavare \\ Portland State University
}

Follow this and additional works at: https://pdxscholar.library.pdx.edu/chem_fac

Part of the Chemistry Commons

Let us know how access to this document benefits you.

\section{Citation Details}

Nabil G. Mistkawi, Makarem A. Hussein, Malgorzata Ziomek-Moroz, and Shankar B. Rananavare, "Corrosion Behavior of Copper Thin Films in Organic HF Containing Cleaning Solution for Semiconductor Applications," J. Electrochem. Soc., 157(1), C24 (2010). 


\title{
Corrosion Behavior of Copper Thin Films in Organic HF-Containing Cleaning Solution for Semiconductor Applications
}

\author{
Nabil G. Mistkawi, ${ }^{a, b}$ Makarem A. Hussein, ${ }^{b}$ Malgorzata Ziomek-Moroz, ${ }^{c}$ and \\ Shankar B. Rananavare ${ }^{\mathrm{a}, \mathrm{z}}$
}

${ }^{a}$ Department of Chemistry, Portland State University, Portland, Oregon 97207-0751, USA

${ }^{b}$ Intel Corporation, Logic Technology Development, Hillsboro, Oregon 97123, USA

'U.S. Department of Energy, National Energy Technology Laboratory, Southwest Albany,

Oregon 97321, USA

\begin{abstract}
The corrosion behavior of electrochemically deposited copper thin films in deaerated and non-deaerated commercial cleaning solutions containing HF was investigated. Potentiodynamic polarization experiments were carried out to determine active, activepassive, passive, and transpassive regions. Corrosion rates were calculated from Tafel slopes. The addition of hydrogen peroxide to the solution and its influence on corrosion was also investigated by employing inductively coupled plasma-mass spectroscopy (ICP-MS) and X-ray photoelectron spectroscopy (XPS). The ICP-MS and potentiodynamic methods yielded comparable Cu dissolution rates. Surface analysis using atomic force microscopy and scanning electron microscopy, performed before and after the cleaning solution treatment, did not reveal any indication of pitting corrosion. The presence of hydrogen peroxide in the cleaning solution led to more than an order of magnitude suppression of copper dissolution rate. We ascribe this phenomenon to the formation of interfacial $\mathrm{CuO}$ detected by XPS on the wafer surface that dissolves at a slower rate in dilute HF (C) 2009 The Electrochemical Society. [DOI: 10.1149/1.3245999] All rights reserved.
\end{abstract}

Manuscript submitted April 28, 2009; revised manuscript received September 15, 2009. Published November $13,2009$.

In the advanced interconnect systems of today, copper is the choice of metallization for ultralarge-scale integration (ULSI). Copper wiring is now employed in all interconnect layers with up to 12 metallization levels in advanced microprocessors. In principle, interconnects are electrical paths or charge carriers made out of metal lines and are separated by insulating interlayer dielectric (ILD) material. The replacement of aluminum alloys by copper mandated prominent changes in integration, metallization, and patterning process technologies. For instance, the introduction of copper in semiconductor devices has brought attention to the phenomena of thinfilm corrosion that must be circumvented for optimal device performance, reliability, and longevity. This has also mandated the adoption of wet etch clean chemistries that are $\mathrm{Cu}$-compatible for the integration of dual damascene (DD) patterning of copper interconnects. A simple two-layer DD interconnect system is illustrated in Fig. 1. In such a system, the electrical signal that allows transistors to communicate with one another and with the outside world is transmitted through the metal lines within any given metallization level and through copper-filled vias from one metallization level to another. In DD integration, the via resistance is mainly determined by the via diameter and thickness, the resistivity of the copper diffusion barrier (DB) being used, and the overall interfacial resistance with the underlying metal layer. Etch residues resulting from plasma etch during patterning process steps may give rise to a high via resistance or even create openings.

There have been many approaches explored to remove the plasma etch residues. These include the use of $\mathrm{O}_{2}, \mathrm{NF}_{3} / \mathrm{Ar}$, and $\mathrm{He} / \mathrm{H}_{2}$ plasma chemistries to clean polymeric residues, ${ }^{1-5}$ as well as the use of wet etch chemistries such as aqueous dilute $\mathrm{HF}^{6}$ and a variety of aqueous solutions, ${ }^{7}$ aqueous solutions containing organic compounds, ${ }^{8}$ and nonaqueous ${ }^{9}$ formulation designs. It is most crucial for a wet etch clean step(s) to be robust with respect to polymer, residue, and metallic and nonmetallic particle removal, as well as to exhibit a high degree of compatibility with exposed substrate materials during the wet etch cleaning process.

The use of copper-compatible clean chemistries to remove these residues and provide an ultraclean surface for the next processing step is a key for better device performance and reliability. If the cleaning solution attacks the copper line, the subsequent barrier and seed deposition processes may exhibit poor coverage over the ex-

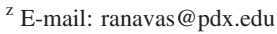

cessively etched area, resulting in an incomplete via fill. ${ }^{10}$ Therefore, understanding molecular mechanisms behind cleaning solutions is essential for developing a successful back-end-of-line (BEOL) process.

The presence of copper-rich residues on the wafer surface after wet clean steps using non-copper-compatible chemistry was detected. Examples of such residues are shown in Fig. 2 and have been the driving force behind this study. Copper corrosion/dissolution during the cleaning process leads to the redeposition/precipitation of copper and copper-rich precipitants onto the wafer surface. The presence of copper on the ILD surface presents serious yield and reliability problems to the performance of ULSI devices. ${ }^{11-14}$ To obtain reliable devices with a low via resistance, the residue on the sidewalls and the bottom of the vias must be removed before the next process step. Similarly, a copper-rich residue may connect metal lines, leading to undesired short circuits.

The objective of this paper is to investigate copper thin-film corrosion/dissolution in aqueous solutions containing HF, organic compounds, and $\mathrm{H}_{2} \mathrm{O}_{2}$ and its relevance to semiconductor DD patterning of copper interconnects. Such solutions are commonly used in the semiconductor industry for post-plasma etch cleaning. Furthermore, we focus on the influence of hydrogen peroxide on copper corrosion from a mechanistic and kinetic standpoint. Hydrogen peroxide is a common component in many cleaning formulations used for particle and residue removal in the fabrication of integrated circuit devices. ${ }^{9,15-20}$ Finally, we discuss several plausible models to explain the observed undesired copper deposition onto the ILD surface.

\section{Experimental}

Substrate.- The experiments were performed using copper on a blanket silicon wafer $(\mathrm{Cu} / \mathrm{Si})$ substrate. The copper film was uniformly deposited using typical industry electroplating equipment ${ }^{21,22}$ followed by a chemical mechanical planarization step to closely mimic the actual $\mathrm{Cu}$ surface during the DD process. The thickness of the $\mathrm{Cu}$ film was approximately $400 \mathrm{~nm}$, as determined by a four-point probe method (surface resistivity meter, Gaurdian Manufacturing Inc., model SRM-232) and cross-section scanning electron microscopy (SEM).

Cleaning solution.-The electrochemical and dissolution experiments were performed utilizing a semiconductor cleaning chemical solution (EG3) supplied by Ashland Chemicals, which was composed of 93 wt \% ethylene glycol, $\sim 4$ wt \% ammonium fluo- 


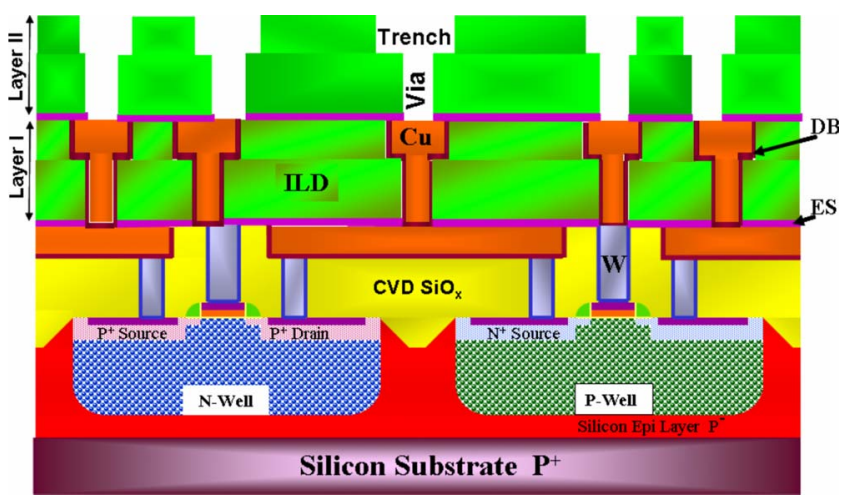

Figure 1. (Color online) A simple two-layer DD interconnect system (not to scale) showing various components such as DB, etch stop layer, and ILD.

ride, 0.033 wt $\% \mathrm{HF}$, and $\sim 3$ wt $\%$ water. The $\mathrm{pH}$ of the cleaning solution was 6.8. All experiments were carried out at room temperature $\left(21^{\circ} \mathrm{C}\right)$.

Surface preparation.-Before proceeding with electrochemical or dissolution experiments, a surface treatment with $0.49 \mathrm{wt} \% \mathrm{HF}$ was carried out to ensure a clean surface. A set of screening experiments to investigate optimal dip time in HF solution for surface cleaning was conducted. A 1 min HF treatment was appropriate. This pretreatment rendered a clean surface on which the native copper oxide was partially removed to expose a clean elemental copper surface. Longer exposure $(\approx 5 \mathrm{~min})$ of the wafer to HF did not alter the X-ray photoelectron spectroscopy (XPS) spectra, which exhibited peaks due to $\mathrm{Cu}(\mathrm{I})$ and $\mathrm{Cu}(0)$. See Fig. 6 (curve A).

\section{Experimental Conditions}

In the electrochemical experiments, copper corrosion was investigated under deaerated, partially deaerated, and non-deaerated solution conditions. Deaeration was achieved by bubbling nitrogen

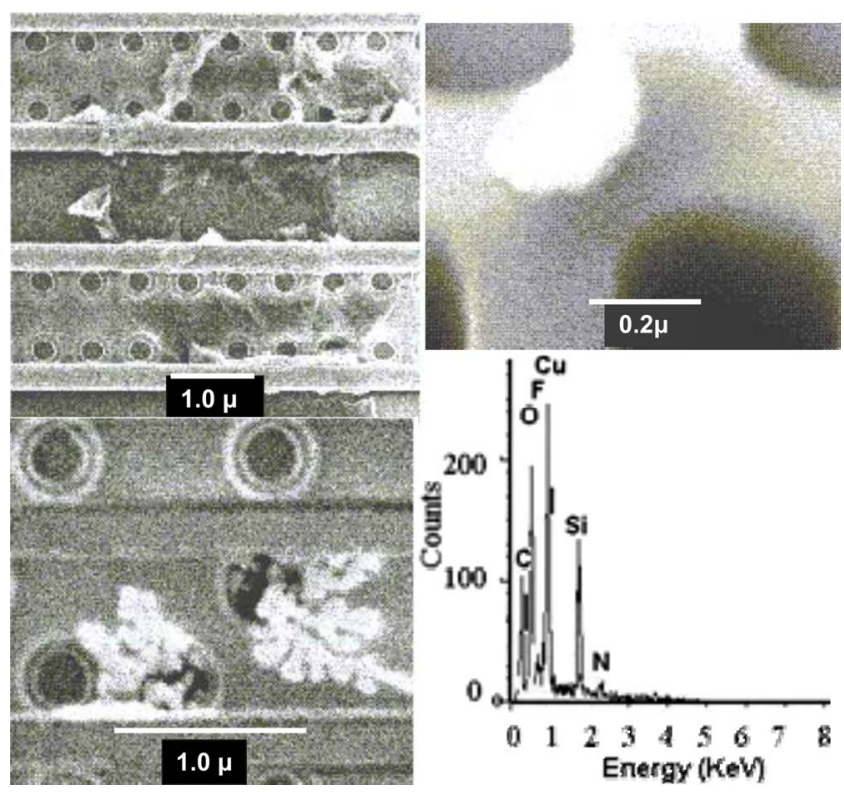

Figure 2. (Color online) SEM micrograph and EDX histogram showing the presence of $\mathrm{Cu}$-rich residues on the ILD surface after wet etch clean steps. Scale bars in the top (left) and bottom (left) SEM images correspond to a length of $1 \mu \mathrm{m}$, while the corresponding scale in the bottom left image corresponds $0.2 \mu \mathrm{m}$. The relative amounts of species shown in the EDX may vary depending on the type of residue. through the solution. Dissolved oxygen (DO) concentration measurements were performed using a digital oxygen meter (Traceable Dissolved Oxygen Meter, Control Co., model RS-232). In the dissolution experiments, copper concentration was monitored using inductively coupled plasma-mass spectroscopy (ICP-MS).

Electrochemical measurements. - The electrochemical experiments were conducted in a three-electrode electrochemical flat cell Platinum mesh was used as the counter electrode. All potentials were measured vs a saturated calomel electrode as a reference electrode. $\mathrm{Cu}$ on a silicon substrate sample with an area of $0.3 \mathrm{~cm}^{2}$ defined by a Viton O-ring was used as the working electrode. A Princeton Applied Research model 273 potentiostat/galvanostat interfaced with an IBM-compatible personal computer was used for data collection. Corrware/Corrview software (Scribner Associates) was used to conduct the experiments and for the data analysis. Experiments were performed in triplicate to ensure reproducibility. For the deaerated and partially deaerated experiments, nitrogen was bubbled through the solution in a round bottom flask, and then the solution was transferred into the electrochemical cell. The concentration of DO in the deaerated, partially deaerated, and nondeaerated solutions was $0.6,2.1$, and $4.5 \mathrm{mg} / \mathrm{L}$, respectively.

OCP experiments. - In these experiments, open-circuit potential (OCP) values or free corrosion potentials were determined for $\mathrm{Cu}$ by immersing the $\mathrm{Cu} / \mathrm{Si}$ sample into the cleaning solution for at least 10 $\min$.

Potentiodynamic experiments.-Polarization curves were obtained to determine the influence of the cleaning solution on the corrosion behavior of the investigated wafers. In each experiment, the potential was scanned at a rate of $10 \mathrm{mV} / \mathrm{min}$ in the anodic direction starting from a potential level of $100 \mathrm{mV}$ more negative than the OCP.

\section{Dissolution Experiments}

Dissolution experiments were carried out using $16 \mathrm{~cm}^{2}$ $(4 \mathrm{~cm} \times 4 \mathrm{~cm}$ ) copper/silicon wafer coupons in a $300 \mathrm{~mL}$ volume of cleaning solution. Aliquots from the cleaning solution containing the copper wafer were collected for ICP-MS analysis at specific intervals to determine copper concentrations. Experiments were performed in three replicates to ensure reproducibility. ICP-MS measurements were performed using the Agilent $7500 \mathrm{CS}$.

The influence of a strong oxidant was investigated by the addition of $\mathrm{H}_{2} \mathrm{O}_{2}$ (J.T. Baker, Inc.) to the cleaning solution. The final $\mathrm{H}_{2} \mathrm{O}_{2}$ concentration in the cleaning solution was $5 \%$. The effect of a commercial corrosion inhibitor, benzotriazol (BTA), was also investigated. For such studies, the cleaning solution contained BTA typically at a $0.5 \%$ concentration level to suppress the copper dissolution in the cleaning solution.

Surface characterization.-SEM and energy dispersive X-ray analysis (EDX) were performed using the Hitachi S-4700. Atomic force microscopy (AFM) images were produced using an atomic force profiler (Dimension, model $V_{x} 330$ ). The XPS survey spectra were obtained using a VG Scientific Theta Probe 300.

\section{Results and Discussion}

Electrochemical corrosion measurements.-OCP measurements.-The OCP measurements for $\mathrm{H}_{2} \mathrm{O}_{2}$-containing, nondeaerated, and partially deaerated cleaning solutions with $\mathrm{Cu}$ film as a working electrode are shown in Fig. 3a-c, respectively. In all cases, the OCP decays exponentially to a final equilibrium value, suggesting that the copper thin film becomes more active in these solutions. In the cleaning solution containing a strong oxidizer, $\mathrm{H}_{2} \mathrm{O}_{2}$, the OCP value settles at $0.291 \mathrm{~V}$ starting from $0.301 \mathrm{~V}$, i.e., about $10 \mathrm{mV}$ change over $5 \mathrm{~min}$. The open-circuit stability indicates that the corrosion of copper is under activation polarization. Intersection of the OCP on the potentiodynamic curve shown in Fig. 4a indicates that the copper is under active corrosion. The shift in corrosion potential 

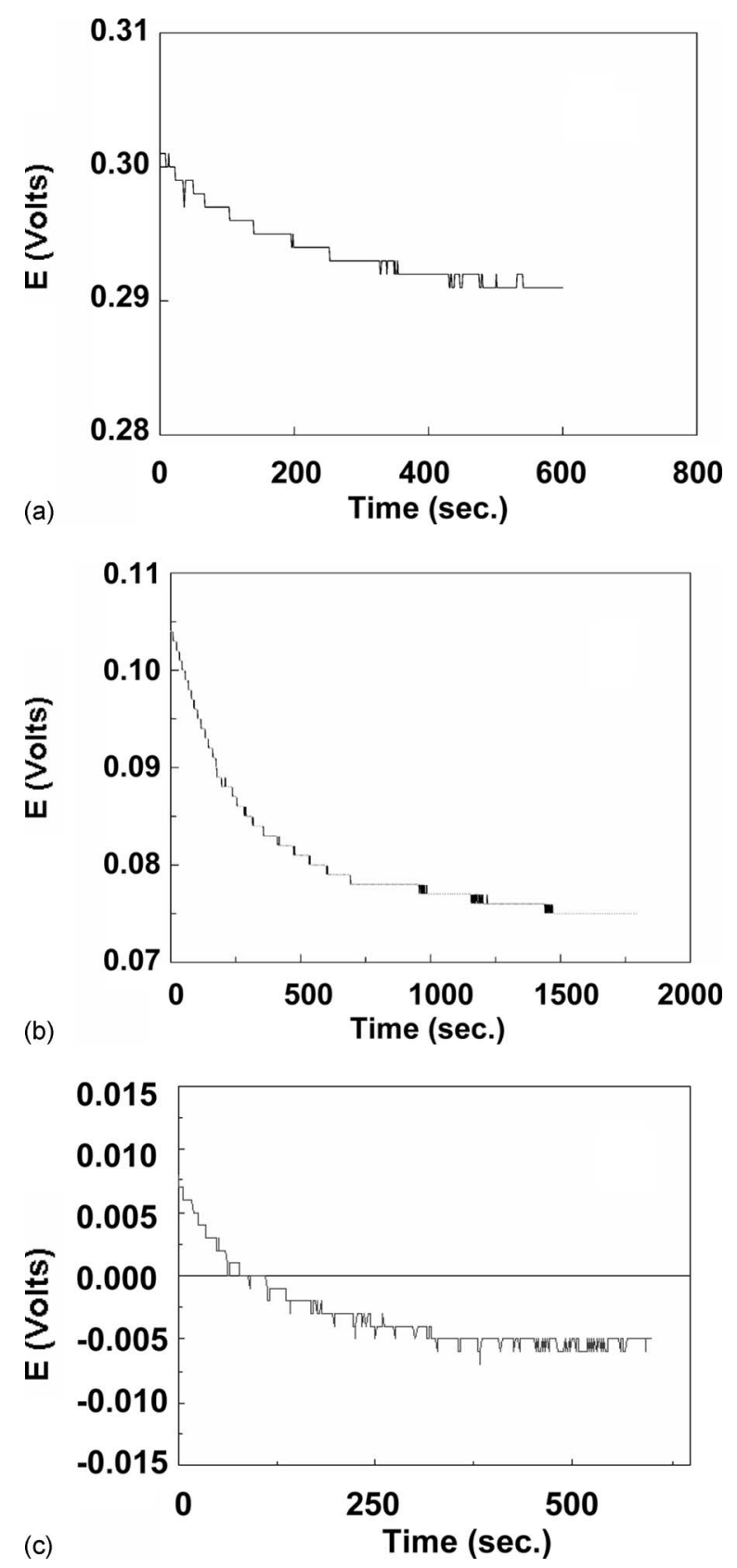

Figure 3. OCP measurements for electrolytic solutions used (a) in the presence of $5 \% \mathrm{H}_{2} \mathrm{O}_{2}$ and in (b) non-deaerated (DO $4.5 \mathrm{mg} / \mathrm{L}$ ) and (c) deareated (DO $0.6 \mathrm{mg} / \mathrm{L}$ ) solutions. The corresponding OCPs are $0.29,0.08$, and $-0.005 \mathrm{~V}$, respectively. The equilbriation period is longer in non-deaerated solutions.

to a nobler potential in Fig. 4a, in comparison to deaerated and non-deaerated samples (Fig. 4b), is consistent with the effect of a strong oxidizer ${ }^{23}$ on an active-passive corroding system (also see below).

The time scale for establishing OCP is longer in a non-deaerated solution, implying a diffusion-controlled process. The OCP potential change in a non-deaerated solution is $\sim 30 \mathrm{mV}$, taking place over a 25 min duration. In addition, comparing the OCP value to the active potential values in the polarization curve of Fig. 4 indicates that copper is active at the OCP. The OCP values depend upon the concentration of DO. Any reduction in oxygen concentration results in a reduction in limiting current density and potential values for the
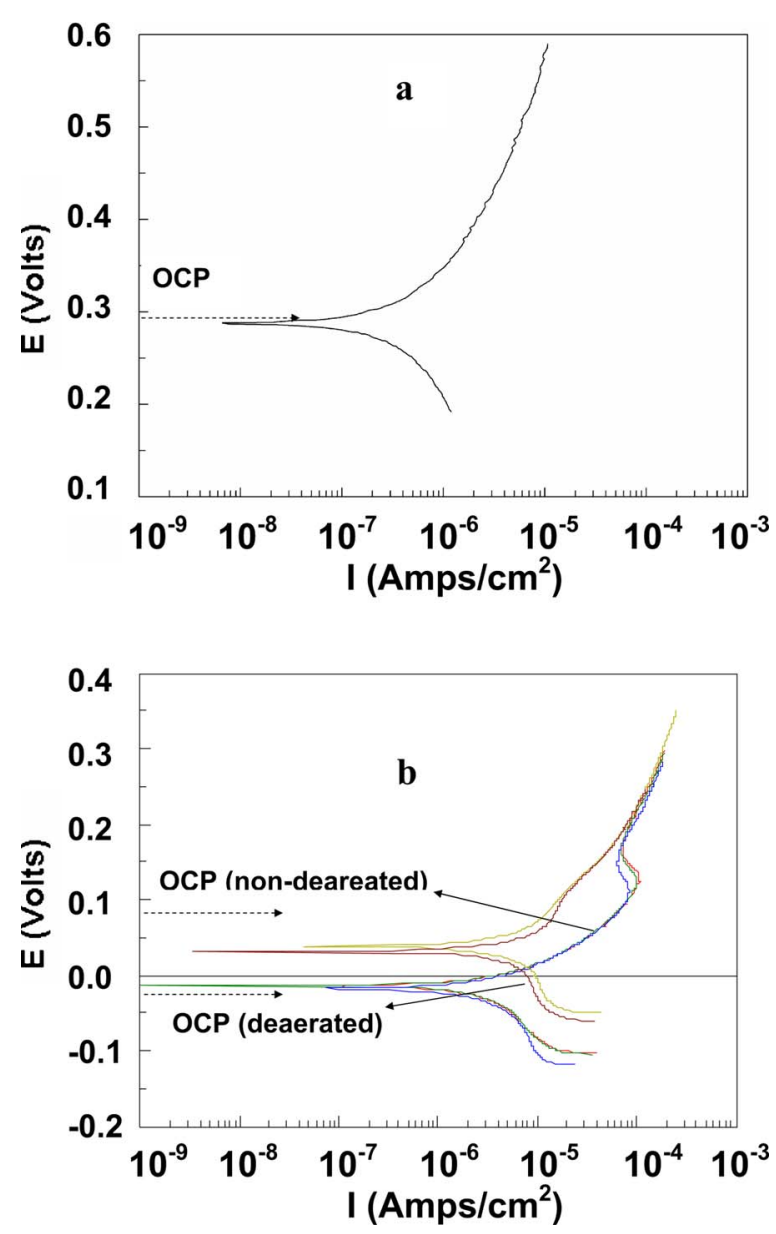

Figure 4. (Color online) Potentiodynamic curves for copper thin films on $\mathrm{Si}$ in cleaning solution containing (a) $\mathrm{H}_{2} \mathrm{O}_{2}$ and under (b) non-deaerated and deaerated conditions. The dashed arrows indicate positions of OCPs, while the full arrows indicate the corresponding potentiodynamic polarization curves.

cathodic reaction causing the open-circuit decay. This indicates that the corrosion of copper is under concentration polarization.

In the deaerated solution, the potential change is only $\sim 10 \mathrm{mV}$ during the first few minutes and reaches a steady state after $\sim 5$ min. The open-circuit stability shows that the corrosion of copper is under activation polarization.

Potentiodynamic experiments. - The results of the potentiodynamic experiments, namely, anodic polarization curves for copper obtained in the hydrogen peroxide-containing and partially deaerated and non-deaerated cleaning solutions, are shown in Fig. 4a and $\mathrm{b}$, respectively. The corrosion behavior of copper in the cleaning solution up to $0.2 \mathrm{~V}$ is affected by the DO concentration. Higher current values are observed for $\mathrm{Cu}$ in the non-deaerated solution up to $0.2 \mathrm{~V}$. Above this potential, the current values are similar for $\mathrm{Cu}$ in the deaerated and non-deaerated cleaning solutions. The shapes of the anodic polarization curves for $\mathrm{Cu}$ in the deaerated and oxygencontaining solutions are different from each other. In the deaerated solution, the current values increase with increasing potential values above $\sim 0.05 \mathrm{~V}$. This indicates the presence of an active region in which metal dissolution takes place. In the non-deaerated solutions, the current values increase with increasing potential values from $\sim-0.02$ to $0.12 \mathrm{~V}$, indicating the presence of an active region. Then, the current values decrease with increasing potentials to $\sim 0.14 \mathrm{~V}$, indicating the presence of an active-passive region. A constant current is observed between $\sim 0.14$ and $\sim 0.17 \mathrm{~V}$, indicating the presence of a passive region. Above the passive region, the current val- 

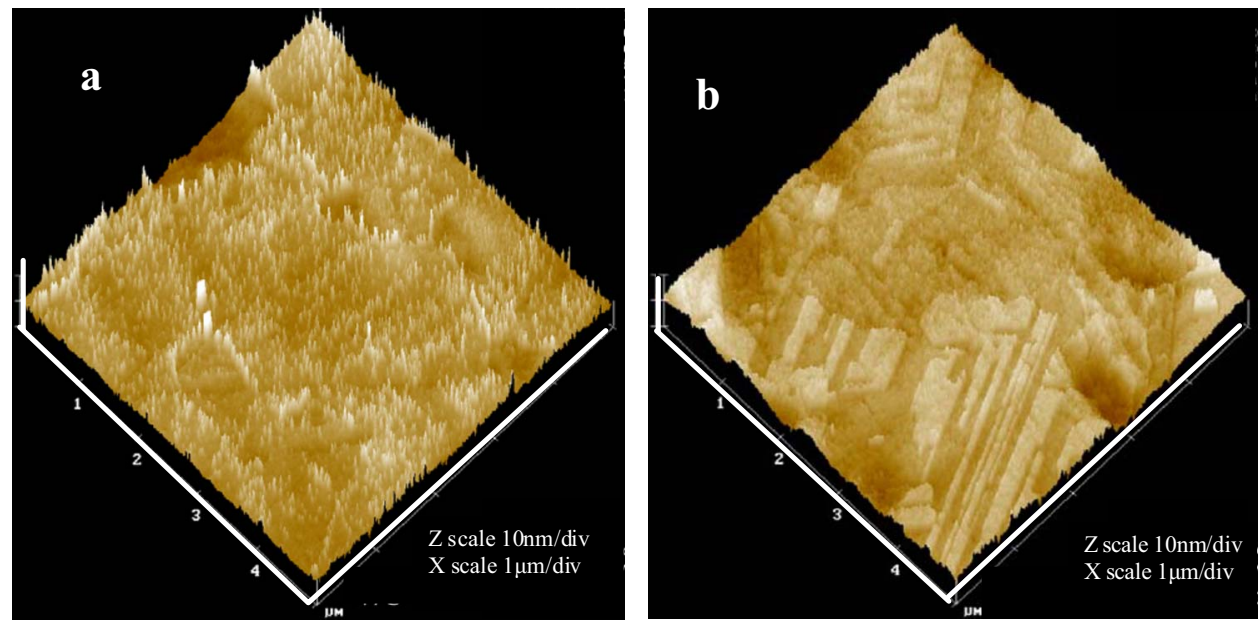

Figure 5. (Color online) AFM images of the copper surface before and after immersion in the cleaning solution shown in (a) and (b), respectively.

ues increase with increasing the potential values applied. The critical passivation current $\left(10^{-4} \mathrm{~A} / \mathrm{cm}^{2}\right)$ in the non-deaerated solution is slightly higher than that $\left(8.5 \times 10^{-5} \mathrm{~A} / \mathrm{cm}^{2}\right)$ in the partially deaerated solution. In the active region $\mathrm{Cu}^{2+}$ is likely formed, which is supported by the Pourbaix diagram for the $\mathrm{Cu}$-water system. ${ }^{24} \mathrm{~A}$ relatively high current is observed in the passive region. This indicates that the nonprotective film is formed on the surface. Given the sensitivity of the potentiodynamic scans to DO, the film could be due to the formation of oxide(s) of copper, as explained in the Conclusions section.

The shift in corrosion potential for peroxide-containing solutions is high, extending well above $0.2 \mathrm{~V}$. Above $0.287 \mathrm{~V}$ the current increases with potential, an indication of an active region. However, unlike the non-deaerated/partially deaerated samples, no clearly defined active-to-passive transition is visible in the plot. The low corrosion current density observed at a corrosion potential is consistent with lower copper dissolution rates measured by ICP-MS (see below).

These potentiodynamic polarization experiments were analyzed by employing Corrview software to determine the corrosion rate in terms of the corrosion current density $\left(I_{\text {corr }}\right)$ using Tafel slopes. The corrosion rates for the deaerated and non-deaerated experiments are $0.80 \pm 0.04$ and $2.0 \pm 0.1 \AA / \mathrm{min}$, respectively. Because copper undergoes active dissolution in the cleaning solution, the surface characteristics of the copper thin film were investigated after the cleaning process to confirm the type of corrosion, namely, uniform corrosion. Localized corrosion, such as pitting corrosion, is not observed in the atomic force microscopic images given in Fig. 5b, where the mean surface roughness values before and after exposure to cleaning solution are $3.8 \pm 0.1$ and $0.82 \pm 0.04 \mathrm{~nm}$, respectively.

The XPS spectra (Fig. 6) show the surface compositional changes that take place before and after the cleaning treatment. The vertical lines indicate positions for the various oxidation states of copper. Virgin copper wafers show $\mathrm{Cu}_{2} \mathrm{O}$, while cleaned wafers indicate the presence of both $\mathrm{Cu}_{2} \mathrm{O}$ and $\mathrm{Cu}^{0}$. This suggests that the attack of $\mathrm{HF}$ on $\mathrm{Cu}_{2} \mathrm{O}$ may initiate the corrosion process due to a favorable $\Delta G(\approx-379 \mathrm{~kJ} / \mathrm{mol})$ of the reaction. Two possible mechanisms explain the observation of $\mathrm{Cu}^{0}$ in the XPS data. Stripping $\mathrm{Cu}_{2} \mathrm{O}$ by $\mathrm{HF}$ in the cleaning solution could expose the underlying $\mathrm{Cu}^{0}$, or the disproportionation of $\mathrm{Cu}^{+1}$ species (from HF reaction) could give rise to $\mathrm{Cu}^{0}$. Both mechanisms predict that $\mathrm{Cu}(\mathrm{II})$ species should be present in the cleaning solution.

To test these models and to complement the electrochemical experiments, which indicated active dissolution of copper, we monitored the buildup of copper ions in the cleaning solution using ICPMS, as shown in Fig. 7. These curves can be fitted to a pseudo-firstorder kinetic process. The measured dissolution rates from the extrapolated slopes of the concentration vs time curves at $t=0$ yield values of $10 \mathrm{ppb} / \mathrm{min}$ in a non-deaerated solution (Fig. 7a) and 1 $\mathrm{ppb} / \mathrm{min}$ (Fig. 7b) in a deaerated solution. The rate of copper dissolution is thus strongly dependent on the oxygen concentration. These findings qualitatively agree with electrochemically determined corrosion rates of 2 and $0.8 \AA / \mathrm{min}$ when corrected for the differences in geometric surface areas of the samples.

The dissolution rate declines precipitously when a high $\mathrm{H}_{2} \mathrm{O}_{2}$ concentration is introduced in a non-deaerated cleaning solution. The ICP-MS data (see Fig. 7c) analysis yields a very low copper dissolution rate of $0.15 \mathrm{ppb} / \mathrm{min}$. Such extremely low dissolution rates, on the time scale of the experiment, lead to an apparent zeroth order (straight line) as opposed to the first-order kinetics seen in nonaerated/deaerated solutions. Corrosion rate calculation of the polarization curve shown in Fig. 4a gives a corrosion rate of 0.3 $\AA /$ min, a value that is much lower than either the deaerated or the non-deaerated samples discussed before.

On a molecular level, the interface between copper and cleaning solution differs in the presence of $\mathrm{H}_{2} \mathrm{O}_{2}$. The XPS results shown in Fig. 8 reveal a replacement of $\mathrm{Cu}_{2} \mathrm{O}$ with $\mathrm{CuO}$ on the copper surface perhaps due to oxidation by $\mathrm{H}_{2} \mathrm{O}_{2}$. Similar observations were made by Vazquez et al. ${ }^{25}$ some time ago, suggesting that the peroxide reduction rate is significantly reduced in the presence of $\mathrm{CuO}$ in neutral/basic solutions. The slowdown in a cathodic reduction process would, in turn, reduce the anodic corrosion rate of copper. ${ }^{26,27}$

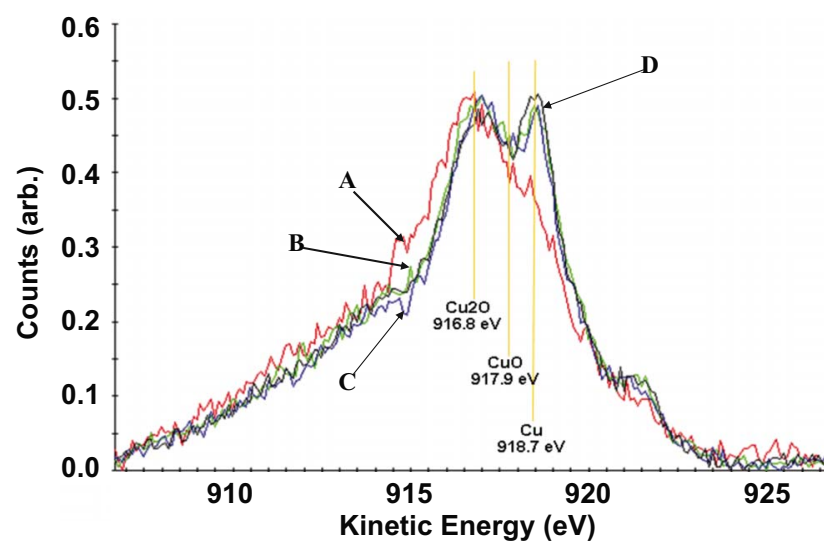

Figure 6. (Color online) XPS spectra of the copper surface before and after surface treatment. The A line corresponds to wafer as received (control), the $\mathrm{B}$ line is the XPS spectrum after surface treatment with $0.49 \% \mathrm{HF}$, and the C and $\mathrm{D}$ lines correspond to wafers that were immersed in the cleaning solution for 6 and $12 \mathrm{~h}$, respectively. 

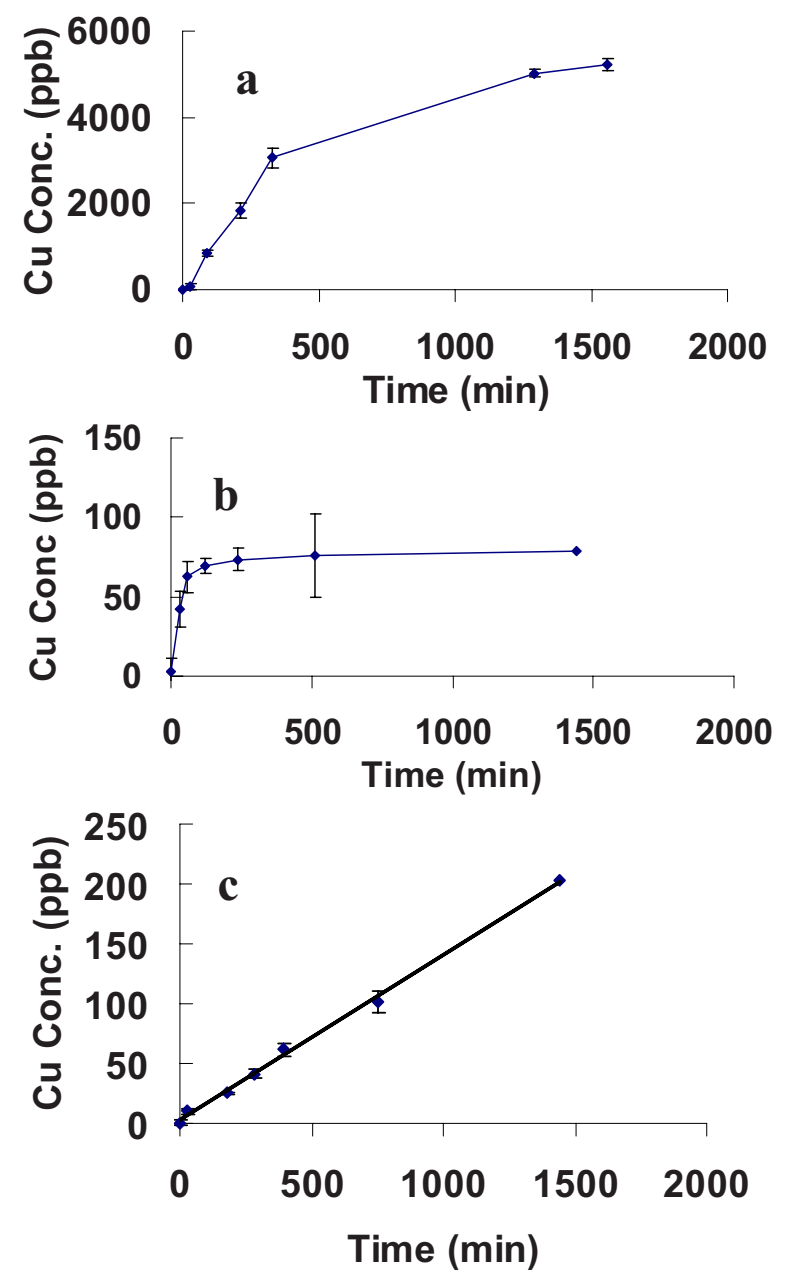

Figure 7. (Color online) $\mathrm{Cu}$ dissolution in (a) non-deaerated and (b) deaerated solutions and (c) in the presence of $\mathrm{H}_{2} \mathrm{O}_{2}$ in the clean solution as a function of time. The DO concentrations were 4.5 and $0.6 \mathrm{mg} / \mathrm{L}$ in the non-deaerated and deaerated solutions, respectively.

The lack of $\mathrm{Cu}(0)$ peaks in the XPS spectrum indicates that a thicker $\mathrm{CuO}$ film covers the copper surface perhaps due to the high concentration of hydrogen peroxide used in this study. The shift in the corrosion potential to nobler values is consistent with peroxide reduction $\left(E^{0}=1.776\right)$ being coupled to an anodic $\mathrm{Cu}$ oxidation, supplanting the normal cathodic oxygen reduction $\left(E^{0}=1.229\right)$ mechanism. At the observed OCP in the peroxide-containing solution, the Pourbaix diagram for copper would predict stability and possible passivity conferred by $\mathrm{CuO}$. The XPS data in Fig. 8 show that $\mathrm{CuO}$ is only observed in peroxide-containing solution, thereby confirming the prediction of the Pourbaix diagram. Thus, an interfacial $\mathrm{CuO}$ may provide an effective corrosion/dissolution barrier in the cleaning solution containing peroxide. An alternate mechanism of surface passivation ${ }^{23}$ in the cleaning solution containing oxidizer $\mathrm{H}_{2} \mathrm{O}_{2}$ could be due to its higher oxidizer concentrations compared to the experiments involving dissolved $\mathrm{O}_{2}$. Therefore, in summary, deaeration/use of $\mathrm{H}_{2} \mathrm{O}_{2}$ can provide a successful strategy for cleaning formulation, which protects the interconnect material.

The chemistry of dissolved copper in the cleaning solution could lead to the copper-rich deposits presented in Fig. 2 through several plausible mechanisms. The simple electroless deposition of copper is $\mathrm{Cu}^{++} \rightarrow \mathrm{Cu}^{0}$, i.e., copper plating out of the solution during the wet cleaning and etching process, as has been suggested by many researchers. ${ }^{14,23,25,28-30}$ Our studies imply that an electroless deposition involving the reduction of cupric ions can be avoided by having an oxidizing species, such as $\mathrm{H}_{2} \mathrm{O}_{2}$, present in the cleaning solution,

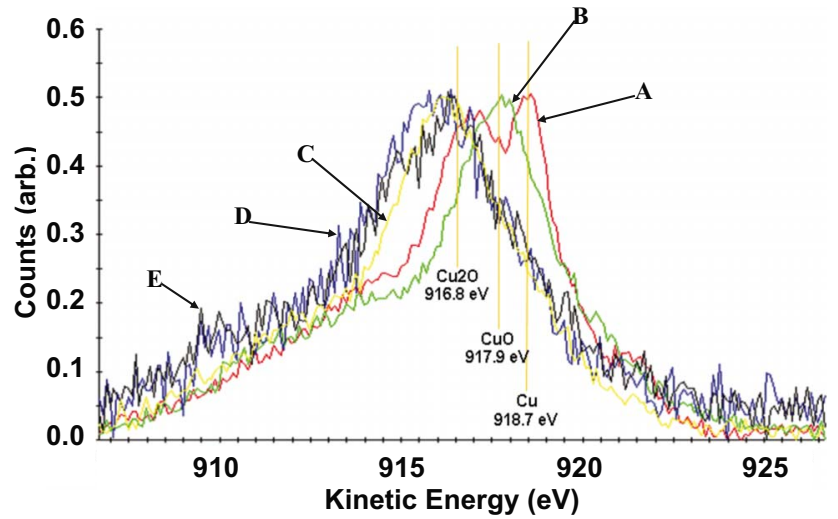

Figure 8. (Color online) XPS spectra of the copper surface before and after wet cleaning solution treatment. The A line corresponds to wafers that were dipped in dilute cleaning solution. The $\mathrm{B}$ line corresponds to wafer processed in dilute cleaning solution containing $5 \% \mathrm{H}_{2} \mathrm{O}_{2}$. The other lines correspond to wafers processed in cleaning solution with a commercial organic corrosion inhibitor, BTA, at different concentrations: C $(0.1 \%), \mathrm{D}(0.5 \%)$, and E $(1.0 \%)$.

provided it is compatible with other solution-exposed interfaces on the wafer. An additional source of copper deposits on the wafer surface may arise from simple precipitation of copper salts and complexes.

It is quite clear that to prevent the formation of copper-rich residues on the ILD surface, copper corrosion must be prevented. Maintaining low copper concentrations allows maintaining of these species below their solubility limits. Similarly, the harmful role of metallic contaminants in creating undesirable deposits is well established for bare silicon wafers ${ }^{12,31-37}$ in support of front-end-of-theline processing. This present study underscores analogous effects of the wafer surface contamination due to products of $\mathrm{Cu}$ interconnect corrosion in BEOL.

One of the limitations of the present study is that it utilized blanket (nonpatterned) wafers and not the copper damascenepatterned wafers. The nanoscaled patterns may exhibit higher corrosion rates ${ }^{38}$ because the dissolution rates are expected to be dependent on several physical factors and film characteristics such as curvature (Kelvin effect), grain size, texture, geometry, and microstructure. ${ }^{39,40}$ Furthermore, with the ever decreasing size of the features on the wafer surfaces, these features provide an overabundance of sites for heterogeneous nucleation. Even with respect to this enhanced deposition mechanism, reducing solution-borne copper concentration lowers the degree of supersaturation and hence the probability of nucleation events.

In addition to the methods used here, one may contemplate using corrosion inhibitors, such as BTA, to passivate the copper surface and prevent copper dissolution. We have established (data not shown here) through ICP-MS-based dissolution studies that such corrosion inhibitors indeed reduce the copper dissolution rates. However, the mechanism for the dissolution suppression appears to be different from that observed in the peroxide-containing solution. When the corrosion inhibitor is used, the copper surface displays $\mathrm{Cu}(\mathrm{I})$ oxide (as shown in Fig. 8, C, D, and E lines), and, presumably, the inhibitor film between the copper surface and the cleaning solution provides the corrosion resistance. Nevertheless, the introduction of such corrosion inhibitors in the cleaning solution could potentially lead to carbon deposits at subsequent processing stages, so the methods presented in this paper might provide suitable alternatives.

\section{Conclusions}

As multistep, multilayer processing in the semiconductor industry becomes more complex, the role of cleaning solutions/ chemistries is becoming important in enhancing yields and in reducing defects. Unwanted residues or deposits occurring over the ILD 
or metallic surfaces containing copper interconnect lines are rich in copper. We have ascribed the origin of copper in these residues to the corrosion processes taking place during cleaning. The potentiodynamic polarization experiments carried out in the cleaning solution show active, active-passive, passive, and transpassive regions. Use of deaerated solutions and possible use of $\mathrm{H}_{2} \mathrm{O}_{2}$ provides an effective method to reduce corrosion rates and copper concentration in a cleaning solution. $\mathrm{H}_{2} \mathrm{O}_{2}$ addition to the cleaning solution appears to be very beneficial by creating a $\mathrm{CuO}$ film that reduces the copper corrosion rate. Furthermore, the incorporation of $\mathrm{H}_{2} \mathrm{O}_{2}$ provides an additional advantage by enhancing the cleaning solution's ability in removing particles and easily oxidizable organic residues.

Intel Corporation assisted in meeting the publication costs of this article.

\section{References}

1. G. S. Oehrlein, G. J. Scilla, and S. Jeng, Appl. Phys. Lett., 52, 907 (1988)

2. G. S. Oehrlein and Y. H. Lee, J. Vac. Sci. Technol. A, 5, 1585 (1987).

3. D. K. Schroder, Materials and Device Characterization, p.576, John Wiley \& Sons, New York (1990).

4. A. Somashekhar, H. Ying, P. B. Smith, D. B. Aldrich, and R. J. Nemanich, J. Electrochem. Soc., 146, 2318 (1999).

5. Q. Han, B. White, I. L. Berry, C. Waldfried, and O. Escorcia, Solid State Phenom., 103-104, 341 (2005)

6. K. Ueno, V. M. Donnelly, and T. Kikkawa, J. Electrochem. Soc., 144, 2565 (1997).

7. T.-H. Park, Y. S. Ko, T. E. Shim, J. G. Lee, and Y.-K. Kim, J. Electrochem. Soc., 142, 571 (1995).

8. W. A. Wojtczak, G. Guan, D. N. Fine, and S. A. Fine, U.S. Pat. 6224785 (2001)

9. W. Kern, J. Electrochem. Soc., 137, 1887 (1990).

10. M. Hussein and J. He, IEEE Trans. Semicond. Manuf., 18, 69 (2005).

11. J. S. Kim, H. Morita, J. D. Joo, and T. Ohmi, J. Electrochem. Soc., 144, 3275 (1997).

12. G. J. Norga, M. Platero, K. A. Black, A. J. Reddy, J. Michel, and L. C. Kimerling, J. Electrochem. Soc., 144, 2801 (1997).

13. L. Mouche, F. Tardif, and J. Derrien, J. Electrochem. Soc., 142, 2395 (1995).

14. G. Li, E. A. Kneer, B. Vermeire, H. G. Parks, S. Raghavan, and J. S. Jeon, J. Electrochem. Soc., 145, 241 (1998).

15. T. Ohmi, T. Imaoka, T. Kezuka, J. Takano, and M. Kogure, J. Electrochem. Soc., 140, 811 (1993)

16. W. Kern and D. A. Puotien, RCA Rev., 31, 187 (1970)

17. N. Awaya, K. Ohno, and Y. Arita, J. Electrochem. Soc., 142, 3173 (1995).
18. T. Shimono and M. Tsuji, in Proceedings of the Second Symposium on Defects in Silicon: Defects in Silicon II, W. M. Bullis and U. Gösele, Editors, p. 361, The Electrochemical Society Proceedings Series, Pennington, NJ (1991).

19. T. Ohmi, T. Imaoka, I. Sugiyama, and T. Kezuka, J. Electrochem. Soc., 139, 3317 (1992).

20. V. Bertagna, F. Rouelle, and M. Chemla, Semicond. Sci. Technol., 13, 444 (1998) 21. P. Singer, Semicond. Int., 21, 90 (1998).

22. D. Edelstein, J. Heidenreich, R. Goldblatt, W. Cote, C. Uzoh, N. Lustig, P. Roper, T. McDevitt, W. Motsiff, A. Simon, et al., Tech. Dig. - Int. Electron Devices Meet., 1997, 773.

23. See, for example, D. A. Jones, Principles and Prevention of Corrosion, 1st ed., p. 119, MacMillan, New York (1991).

24. M. Pourbaix, Atlas of Electrochemical Equilibria in Aqueous Solutions, NACE International, Houston (1974).

25. M. V. Vazquez, S. R. Sanchez, E. J. Calvo, and D. J. Schiffrin, J. Electroanal. Chem., 374, 179 (1994)

26. K. K. Yoneshige, H. G. Parks, S. Ragaavan, J. B. Hiskey, and P. J. Resnick, J. Electrochem. Soc., 142, 671 (1995).

27. J. S. Jeon, S. Raghavan, H. G. Parks, J. K. Lowell, and L. Ali, J. Electrochem. Soc., 143, 2870 (1996)

28. H. Morinaga, M. Suyama, M. Nose, S. Verhaverbeke, and T. Ohmi, IEICE Trans. Electron., 79C, 343 (1996)

29. T. Homma, C. P. Wade, and C. E. D. Chidsey, J. Phys. Chem. B, 102, 7919 (1998).

30. X. Cheng, G. Li, E. A. Kneer, B. Vermeire, H. G. Parks, S. Raghavan, and J. S Jeon, J. Electrochem. Soc., 145, 247 (1998).

31. E. Hsu, H. G. Parks, and R. Craigin, J. Electrochem. Soc., 139, 3659 (1992).

32. X. Cheng, G. Li, E. A. Kneer, B. Vermeire, H. Parks, S. Raghavan, and J. S. Jeon, J. Electrochem. Soc., 145, 352 (1998)

33. O. J. Anttila, M. V. Tilli, M. Schaekers, and C. L. Claeys, J. Electrochem. Soc., 139, 1180 (1992)

34. X. Cheng, C. Gu, and Z.-D. Feng, J. Electrochem. Soc, 150, G112 (2003).

35. E. D'Elia, O. E. Barcia, O. R. Mattos, N. Pébere, and B. Tribollet, J. Electrochem Soc., 143, 961 (1996)

36. V. Bertagna, F. Rouelle, G. Revel, and M. Chemla, J. Electrochem. Soc., 143, 3532 (1996)

37. O. M. R. Chyan, J. J. Chen, H. Y. Chien, J. Sees, and L. Hall, J. Electrochem. Soc. 143, 92 (1996)

38. D. Ernur, V. Terzieva, W. Wu, S. H. Brongersma, and K. Maex, J. Electrochem. Soc., 151, B636 (2004)

39. D. Ernur, L. Carbonell, and K. Maex, in Materials Research Society Spring Meet ing, Symposium Z, Materials Research Society (2003).

40. P. R. Besser, E. Zschech, W. Blum, D. Winter, R. Ortega, S. Rose, M. Herrick, M Gall, S. Thrasher, M. Tiner, et al, J. Electron. Mater, 30, 320 (2001). 